\title{
$\alpha$-adrenoceptor-mediated enhanced inducibility of atrial fibrillation in a canine system inflammation model
}

\author{
YING-YING CHEN ${ }^{1}$, ZE-WEI SUN ${ }^{2}$, JIAN-PING JIANG ${ }^{3}$, XIAO-DONG KANG ${ }^{4}$, \\ LIN-LIN WANG $^{5}$, YUE-LIANG SHEN ${ }^{1}$, XU-DONG XIE $^{2}$ and LIANG-RONG ZHENG ${ }^{2}$
}

\begin{abstract}
${ }^{1}$ Department of Pathology and Pathophysiology, Zhejiang University School of Medicine, Hangzhou, Zhejiang 310058;
${ }^{2}$ Department of Cardiology, The First Affiliated Hospital, Zhejiang University School of Medicine, Hangzhou, Zhejiang 310003; ${ }^{3}$ Department of Clinical Medicine, Zhejiang Medical College, Hangzhou, Zhejiang 310053;

${ }^{4}$ Experimental Animal Center, Hangzhou Normal University, Hangzhou, Zhejiang 311121; ${ }^{5}$ Center for Stem Cell and Tissue Engineering, Zhejiang University School of Medicine, Hangzhou, Zhejiang 310058, P.R. China
\end{abstract}

Received October 10, 2015; Accepted February 23, 2017

DOI: $10.3892 / \mathrm{mmr} .2017 .6477$

\begin{abstract}
The exact mechanism associated with inflammation and atrial fibrillation (AF) remains unknown. The aim of the present study was to investigate the roles of connexin 43 (Cx43) and a1-adrenergic receptor ( $\alpha 1-\mathrm{AR})$ activation in the pathogenesis of system inflammation-induced AF. A canine model of chronic low-grade system inflammation was established by administrating a low dose of lipopolysaccharide (LPS; $0.1 \mu \mathrm{g} / \mathrm{kg}$ ) for 2 weeks. Programmed stimulation was applied on the right atrial appendage to determine the effective refractory periods (ERP) and the window of vulnerability (WOV). Tumor necrosis factor $\alpha$ (TNF- $\alpha$ ) and interleukin 6 (IL-6) levels in plasma and atrial tissue were measured by ELISA. Cx43, Toll-like receptor 4 (TLR4) and nuclear factor $\kappa \mathrm{B}(\mathrm{NF}-\kappa \mathrm{B})$ proteins were analyzed using western blotting or immunohistochemistry. Administration of LPS for 2 weeks increased the concentration of TNF- $\alpha$ and IL-6 in the plasma and right atrium. ERP was markedly shortened and cumulative WOV was significantly widened in the LPS group. Following treatment with LPS, the amount of Cx43 protein in the area of intercalated disk increased. In addition, a high-density of $\mathrm{Cx} 43$ in the lateral connection was identified. LPS also induced the activation of NF- $\mathrm{KB}$ in the canine atrium. Administration with the $\alpha 1$-AR blocker doxazosin prevented the production of LPS-induced inflammatory cytokine and reversed the enhanced vulnerability to atrial fibrillation. Doxazosin inhibited the LPS-induced increase in $\mathrm{Cx} 43$ protein and heterogeneous distribution, and prevented the activation of
\end{abstract}

Correspondence to: Dr Liang-Rong Zheng, Department of Cardiology, The First Affiliated Hospital, Zhejiang University School of Medicine, 79 Qingchun Road, Hangzhou, Zhejiang 310003, P.R. China

E-mail: zlrylnn@126.com

Key words: atrial fibrillation, inflammation, connexin 43, a1-adrenoreceptor
NF-кB. These results indicated that chronic low-grade system inflammation may increase the inducibility of AF in a canine model. The underlying mechanism may be involved in the LPS-induced activation of NF- $\kappa \mathrm{B}$, and the increase in $\mathrm{Cx} 43$ expression and lateral distribution via an $\alpha 1$-AR-dependent pathway.

\section{Introduction}

Atrial fibrillation (AF) is the most common cardiac arrhythmia $(1,2)$. The majority of patients with AF have underlying cardiovascular diseases, including valvular heart disease, coronary artery disease, cardiomyopathy and diabetes mellitus (3). A number of studies have indicated that inflammation serves an important role in the pathogenesis of AF (4-6). Patients with AF have been identified to have an elevated level of serum inflammatory markers including C-reactive protein (CRP), interleukin 6 (IL-6), tumor necrosis factor $\alpha$ (TNF- $\alpha$ ) and monocyte chemoattractant protein-1 (MCP-1) $(5,7,8)$. Histological studies have demonstrated that inflammatory cell infiltration increases in the atrial myocardium of patients with AF $(6,9)$. Treatment with anti-inflammatory agents has been demonstrated to decrease the recurrence and perpetuation of $\mathrm{AF}(10,11)$. In addition, alterations in the expression of connexins and remodeling is involved in the pathogenesis of $\mathrm{AF}$ (12). Connexin 43 (Cx43) is one of the major connexin isotypes in the atrial myocardium (13). Previous studies have indicated that there is a link between Cx43-mediated gap-junction coupling and atrial arrhythmias (14-16). Under physiological conditions, $\mathrm{Cx} 43$ is localized in intercalated disks between atrial myocytes. Lateralization of $\mathrm{Cx} 43$ has been observed in patients with $\mathrm{AF}(14)$ and in the chronic pressure overload-induced AF animal model (17). However, it remains unclear whether Cx43 is involved in inflammation-induced atrial fibrillation.

There is an increasing body of evidence that demonstrates that there may be cross-talk between $\alpha$-adrenergic receptor $(\alpha-A R)$ signaling and the immune system during inflammation. Flierl et al (18) reported that phagocytes are capable of de novo production of catecholamines when phagocytes are 
exposed to lipopolysaccharides (LPS), producing a blockade of $\alpha 2$-AR, which suppressed lung inflammation. A significant increase in $\alpha 1-\mathrm{AR}$ expression has been observed in human periodontal ligament fibroblasts following LPS pretreatment and blocking $\alpha 1-\mathrm{AR}$ signaling prevents the upregulation of inflammatory-associated cytokines (19). In high altitude native rats, blockage of the $\alpha$-AR also induced a complete decrease in inflammatory mediators (20). Therefore, it was hypothesized that $\alpha 1$-adrenergic activation may be involved in inflammation-induced AF.

In the present study, dogs were administrated a low dose of LPS for 2 weeks to mimic the chronic low-grade system of inflammation. The roles of $\mathrm{Cx} 43$ and $\alpha 1-\mathrm{AR}$ in inflammation-induced $\mathrm{AF}$ were then investigated.

\section{Materials and methods}

Animals. A total of 20 healthy male beagles (weight, $10-12 \mathrm{~kg}$; age, 12-15 months old) from the Experimental Animal Center of Hangzhou Normal University (Hangzhou, Zhejiang, China), with no prior symptoms of inflammation or AF, were used. The dogs were housed in individual cages in a controlled room (18 to $24^{\circ} \mathrm{C}$ with a $12 / 12 \mathrm{~h}$ light/dark cycle) for 2 weeks prior to the experiment and were given free access to food and water. The investigation conformed to the Guide for the Care and Use of Laboratory Animals published by the US National Institutes of Health (21). All experimental protocols were approved by the Ethics Committee on Experimental Animal Center of Hangzhou Normal University (Hangzhou, China).

Drugs and solutions. LPS (derived from Escherichia coli 055:B5) and doxazosin were purchased from Sigma-Aldrich; Merck KGaA (Darmstadt, Germany). Sodium pentobarbital was purchased from Sinopharm Chemical Reagent Co., Ltd. (Shanghai, China). Cx43 (cat. no. \#3512), nuclear factor $\kappa B(\mathrm{NF}-\kappa \mathrm{B})$ p65 (cat. no. \#8242), histone H3 (cat. no. \#9717) and $\beta$-actin (cat. no. \#4970) antibodies were purchased from Cell Signaling Technology, Inc. (Danvers, MA, USA). Toll-like receptor 4 (TLR4) antibody (cat. no. LS-C44226) was obtained from LifeSpan BioSciences, Inc. (Seattle, WA, USA). The enzyme-linked immunosorbent assay (ELISA) kits for TNF- $\alpha$ (cat. no. CATA00) and IL-6 (cat. no. CA6000) were from R\&D Systems, Inc. (Minneapolis, MN, USA).

Experimental protocol. The dogs were divided into four groups of 5 dogs each. Dogs in the control group were injected with the same volume of vehicle $[0.9 \% \mathrm{NaCl}, 0.2 \mathrm{ml} / \mathrm{kg}$, intraperitoneal (i.p.)] and fed empty capsules once a day for 2 weeks. Dogs in the LPS group received LPS $(0.1 \mu \mathrm{g} / \mathrm{kg}$ in $0.9 \% \mathrm{NaCl}$, i.p.) and fed empty capsules once a day for 2 weeks. In the LPS + doxazosin group, the dogs were fed $\alpha 1-\mathrm{AR}$ antagonist doxazosin $(0.2 \mathrm{mg} / \mathrm{kg})$ in the form of a capsule $5 \mathrm{~min}$ following LPS injection. Dogs in the doxazosin group were fed a capsule containing doxazosin $(0.2 \mathrm{mg} / \mathrm{kg}) 5 \mathrm{~min}$ following an i.p. injection of $0.9 \% \mathrm{NaCl}$.

Vital signs monitoring. Vital signs (i.e., rectal temperature, heart rates and blood pressure) were observed and recorded at time $0 \mathrm{~h}$ (prior to the experiment) and 3, 6, 12 and $24 \mathrm{~h}$ following each injection of LPS. For noninvasive measurement of blood pressure, a cuff was placed on the right femoral region and connected to a commonly used noninvasive blood pressure monitor. Heart rate was measured by palpations of the femoral pulse.

Measurement of systemic TNF- $\alpha$ and IL- 6 levels. Blood ( $2 \mathrm{ml})$ was collected in EDTA-coated tubes at $3 \mathrm{~h}$ and then 1, 4, 7 and 14 days post-treatment with the first injection of LPS. The plasma was separated by centrifugation at 2,000 $\mathrm{x}$ g for $10 \mathrm{~min}$ at room temperature, and then stored at $-80^{\circ} \mathrm{C}$ until analysis. The systemic TNF- $\alpha$ and IL-6 levels were determined by Canine TNF- $\alpha$ Quantikine ELISA kit (cat. no. CATA00) and Canine IL-6 Quantikine ELISA kit (cat. no. CA6000) according to the manufacturer's instructions (R\&D Systems, Inc.).

Animal preparation. Following 2 weeks of the different treatment, the dogs were fasted for $\geq 10$ to $12 \mathrm{~h}$ and then anesthetized with sodium pentobarbital ( $30 \mathrm{mg} / \mathrm{kg}$, i.p.). A multi-electrode catheter (Cordis Webster, Inc.; Biosense Webster, Inc.; Johnson \& Johnson, New Brunswick, NJ, USA) was introduced from the right external jugular vein and was placed in the right atrial appendage to record right atrial electrograms and for atrial pacing. The pacing and recording leads were connected to a cardiac electrophysiology stimulator (model DF-5A; Suzhou Dongfang Electronic Instrument Factory, Shuzhou, China) and a multichannel electrophysiological recording system (model TOP-2001; Shanghai Hongtong Industrial Co., Shanghai, China). ECGs were recorded with the use of bipolar percutaneous electrodes placed in each of the dogs' four limbs. Body temperature was maintained at $36.5 \pm 1.5^{\circ} \mathrm{C}$ using a heating pad situated under the dog. Anesthesia was maintained with $6 \mathrm{mg} / \mathrm{kg}$ of sodium pentobarbital i.p. administration hourly.

Programmed stimulation. Programmed stimulation was used to determine the atrial effective refractory periods (ERP) and window of vulnerability (WOV). The right atrium was paced at an atrial pacing cycle length of $300 \mathrm{msec}$; electrical pacing was repeated every $300 \mathrm{msec}$ with each pace lasting $0.5 \mathrm{msec}$ in duration. The ERP at $2 \mathrm{x}, 4 \mathrm{x}$ and $10 \mathrm{x}$ diastolic threshold was determined by programmed stimulation of the right atrial appendage, which consisted of 8 consecutive stimuli ( $\mathrm{S} 1 \mathrm{~S} 1=300 \mathrm{msec}$ ) followed by a premature stimulus (S1S2). The S1S2 intervals were decreased from $200 \mathrm{msec}$ to refractoriness by decrements of $2 \mathrm{msec}$. As the S1S2 intervals approached the ERP, decrements were reduced to $1 \mathrm{msec}$. The atrial ERP was defined as the longest S1-S2 interval that failed to induce atrial depolarization (22).

The WOV was used as a quantitative measurement of AF inducibility. AF was defined as irregular atrial rates faster than $500 \mathrm{bpm}$ associated with irregular atrioventricular conduction lasting longer than $5 \mathrm{sec}$. During ERP measurements, if AF was induced by decremental S1S2 stimulation, the difference between the longest and shortest S1-S2 interval (in msec) at which AF was induced was defined as the WOV. The cumulative WOV was the sum of the individual WOVs determined at $2 \mathrm{x}, 4 \mathrm{x}$ and 10x threshold levels in each dog (23).

The ability of the atria to develop sustained AF was also analyzed by burst pacing at 10x threshold (S1S1=100 msec and $50 \mathrm{msec}$ ) for $120 \mathrm{sec}$. Sustained AF was defined as a fast 
irregular rhythm that lasted for $>60 \mathrm{sec}$ following cessation of burst pacing (24).

Cardiac TNF- $\alpha$ and IL- 6 content analyses. Following the measurements for AF inducibility, right atrial tissues from all 20 dogs were harvested and homogenized thoroughly on ice in a lysis buffer (50 mM Tris-HCl, $0.1 \mathrm{mM}$ EDTA-2Na, $1 \mathrm{mM}$ sucrose, $0.8 \%$ sodium chloride, $\mathrm{pH} 7.4$ ). The homogenates were centrifuged at $12,000 \mathrm{x} \mathrm{g}$ and $4^{\circ} \mathrm{C}$ for $10 \mathrm{~min}$, and the supernatant was collected and stored at $-80^{\circ} \mathrm{C}$ until analysis. The TNF- $\alpha$ and IL- 6 levels in the supernatant were measured using the Canine TNF- $\alpha$ Quantikine ELISA kit (cat. no. CATA00) and Canine IL-6 Quantikine ELISA kit (cat. no. CA6000) according to the manufacturer's instruction (R\&D Systems, Inc.). Protein concentration of the supernatant was determined using a bicinchoninic acid protein assay kit (Beyotime Institute of Biotechnology, Haimen, China) according to the manufacturer's instructions. The cardiac TNF- $\alpha$ and IL- 6 contents were expressed as picograms per milligram of protein.

Western blot analysis. Total proteins were obtained from right atrial myocardium by homogenization in ice-cold radioimmunoprecipitation lysis solution (Cell Signaling Technology, Inc.) containing $1 \%$ Triton X-100, phosphatase, protease inhibitors and PMSF. Nuclear protein extracts were obtained using a Nuclear and Cytoplasmic Protein Extraction kit and quantified using a bicinchoninic kit (Beyotime Institute of Biotechnology) according to the manufacturer's instructions. Equal amounts of protein $(20 \mu \mathrm{g})$ from each sample were separated by $10 \%$ SDS-PAGE and transferred to a nitrocellulose membrane (EMD Millipore, Billerica, MA, USA). The membranes were blocked for $1 \mathrm{~h}$ with $5 \%$ bovine serum albumin (BSA) at room temperature, then incubated overnight at $4^{\circ} \mathrm{C}$ with the primary antibodies, including anti-Cx43 $(1: 1,000)$, anti-TLR4 (1:500), anti-NF- $\mathrm{B}$ p65 $(1: 1,000)$, anti- $\beta$-actin $(1: 1,000)$ and anti-histone H3 (1:1,000). Following washing using TBS-T (Tris-buffered saline with $0.1 \%$ Tween-20), the membrane was incubated with a horseradish peroxidase-conjugated secondary antibody [1:1,000; goat anti-rabbit IgG (cat. no. \#7074) or horse anti-mouse IgG (cat. no. \#7076); Cell Signaling Technology, Inc.] for $45 \mathrm{~min}$ at room temperature. All reactions were detected using an enhanced chemiluminescence kit (Beyotime Institute of Biotechnology) according to manufacturer's instructions. The experiment was repeated three times. The band intensities were analyzed with Quality One software (version 4.6.2; Bio-Rad Laboratories, Inc., Hercules, CA, USA).

Immunohistochemistry. Immunohistochemistry staining was used to determine the localization of $\mathrm{Cx} 43$ in the atria. Each tissue section (5- $\mu \mathrm{m}$ thick) was deparaffinized, rehydrated and blocked with $5 \%$ BSA for $1 \mathrm{~h}$ at room temperature. Then, the sections were incubated with the anti-Cx43 antibody (dilution, 1:500) overnight at $4{ }^{\circ} \mathrm{C}$, followed by incubation with the biotin-conjugated secondary antibody (dilution, 1:200; cat. no. A0277; Beyotime Institute of Biotechnology) for $1 \mathrm{~h}$ at room temperature. Nuclei were counterstained with hematoxylin staining solution (cat. no. C0107; Beyotime Institute of Biotechnology) for $5 \mathrm{~min}$ at room temperature. Staining was visualized using 3,3-diaminobenzidine (DAB). The sections were then observed and photographed under the BX51 microscope (Olympus Corporation, Tokyo, Japan). To quantify staining for $\mathrm{Cx} 43$ in the analyzed regions, integrated optical density was calculated as the product of staining area and intensity using image analysis software (Image-Pro Plus version 6.0.0.26; Media Cybernetics, Inc., Rockville, MD, USA).

Statistical analysis. Data are expressed as the mean \pm standard error and were analyzed by one-way analysis of the variance (ANOVA) with Newman-Keuls' post hoc tests, or two-way ANOVA with Bonferroni post hoc tests as required using Prism v6.0 (GraphPad Software, Inc., La Jolla, CA, USA). $\mathrm{P}<0.05$ was considered to indicate a statistically significant difference.

\section{Results}

Effect of LPS on vital signs. The dogs in the control and doxazosin only groups had no visible symptoms including, fever, lethargy, vomiting, diarrhea or increased heart rate. In the LPS only group, all dogs treated with LPS $(0.1 \mathrm{mg} / \mathrm{kg} ; \mathrm{n}=5)$ developed fever and lethargy within $3 \mathrm{~h}$. Signs of increased gastrointestinal motility, such as vomiting $(1 / 5)$ and diarrhea (4/5), were observed within $6 \mathrm{~h}$ following the first LPS administration. However, these symptoms disappeared within $24 \mathrm{~h}$ and did not recur throughout the study. The dogs in the LPS + doxazosin group developed the same symptoms following the first LPS treatment and all symptoms disappeared within $24 \mathrm{~h}$. Heart rate increased within $6 \mathrm{~h}$ and peaked at $12 \mathrm{~h}$, then returned to normal in both the LPS and LPS + doxazosin groups. Treatment with LPS and/or doxazosin for 2 weeks did not alter body weight, the mean arterial blood pressure or heart rate. All dogs completed the study without mortality. Data are not shown.

Effect of LPS on inflammatory factor and inducibility of AF. When compared with the control group, plasma TNF- $\alpha$ and IL-6 levels increased at $3 \mathrm{~h}$ following treatment with LPS, then returned to normal levels at $24 \mathrm{~h}$ following treatment. However, administration of LPS for 3 to 14 days increased plasma TNF- $\alpha$ concentration over 6-fold. Similarly, the level of plasma IL-6 increased by $\sim 10$-fold following 3-14 days of LPS injection $(\mathrm{P}<0.01$; Fig. 1). The TNF- $\alpha$ and IL-6 contents in the atrial tissue were also significantly increased in the LPS group when compared with the control $(\mathrm{P}<0.01$; Fig. 2$)$. The concentrations of TNF- $\alpha$ and IL- 6 were not altered in the doxazosin only group when compared with the control group (Figs. 1 and 2). When compared with the control group, the levels of TNF- $\alpha$ and IL-6 were higher in the LPS + doxazosin group. However, the TNF- $\alpha$ content and level of IL- 6 was significantly lower in the LPS + doxazosin group when compared with the LPS only group $(\mathrm{P}<0.01$; Figs. 1 and 2$)$.

Following treatment with LPS $(0.1 \mu \mathrm{g} / \mathrm{kg}$, daily) for 2 weeks, ERP was significantly shortened at either $2 \mathrm{x}, 4 \mathrm{x}$ or 10x threshold and the cumulative WOV was significantly widened in the LPS group ( $\mathrm{P}<0.01$ vs. control; Fig. 3). Burst pacing at $10 \mathrm{x}$ threshold failed to develop sustained AF in the control group, however, it did induce the occurrence of sustained AF in 3/5 dogs treated with LPS. Doxazosin alone did not influence the ERP and cumulative WOV (P>0.05; vs. 
A

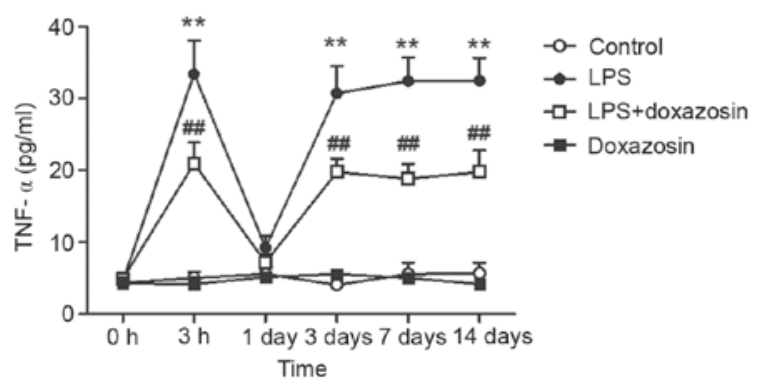

B

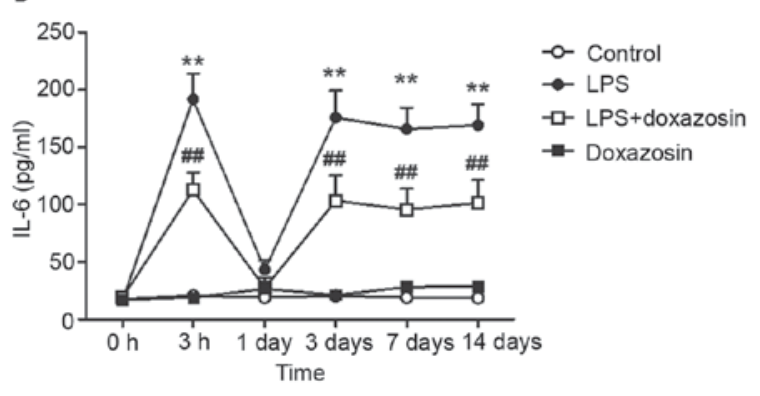

Figure 1. Effect of LPS on systemic inflammatory factors in canines. (A) Plasma TNF- $\alpha$ levels and (B) plasma IL-6 levels were measured in canines from the control (vehicle), LPS $(0.1 \mu \mathrm{g} / \mathrm{kg}$ LPS), LPS + doxazosin $(0.1 \mu \mathrm{g} / \mathrm{kg} \mathrm{LPS}+0.2 \mathrm{mg} / \mathrm{kg}$ doxazosin) and doxazosin only $(0.2 \mathrm{mg} / \mathrm{kg}$ doxazosin) groups, at $3 \mathrm{~h}$, and 1, 3, 7 and 14 days following LPS injection. Data are expressed as the mean \pm standard error $(\mathrm{n}=5 /$ group $) .{ }^{* *} \mathrm{P}<0.01$ vs. control; ${ }^{\# \#} \mathrm{P}<0.01$ vs. LPS. LPS, lipopolysaccharide; TNF- $\alpha$, tumor necrosis factor $\alpha$; IL-6, interleukin 6 .
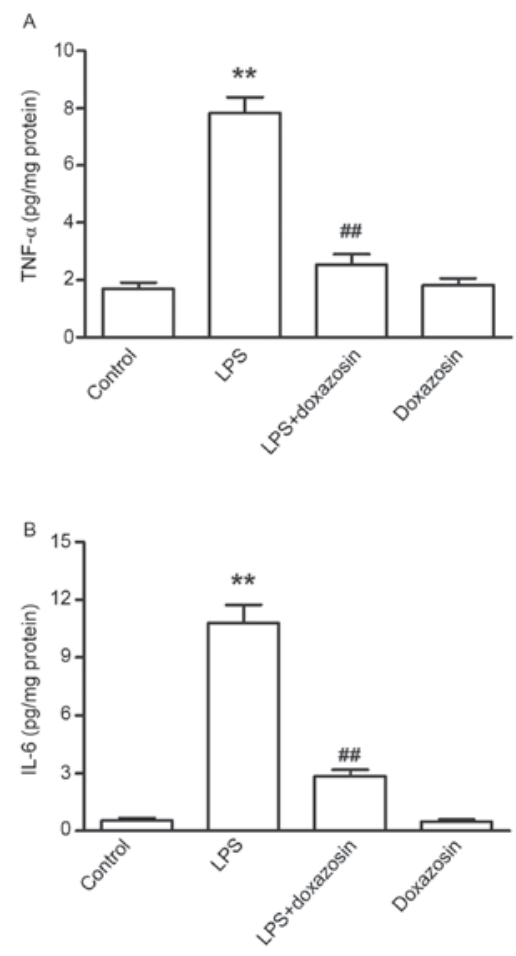

Figure 2. Effect of LPS on inflammatory factors in canine right atrium. (A) Cardiac TNF- $\alpha$ level and (B) cardiac IL-6 levels were measured in canines from the control (vehicle), LPS $(0.1 \mu \mathrm{g} / \mathrm{kg}$ LPS), LPS + doxazosin $(0.1 \mu \mathrm{g} / \mathrm{kg}$ LPS $+0.2 \mathrm{mg} / \mathrm{kg}$ doxazosin) and doxazosin only $(0.2 \mathrm{mg} / \mathrm{kg}$ doxazosin) groups. Data are expressed as the mean \pm standard error ( $\mathrm{n}=5 /$ group). ${ }^{* *} \mathrm{P}<0.01$ vs. control; ${ }^{\# \#} \mathrm{P}<0.01$ vs. LPS. LPS, lipopolysaccharide; TNF- $\alpha$, tumor necrosis factor $\alpha$; IL-6, interleukin 6 .

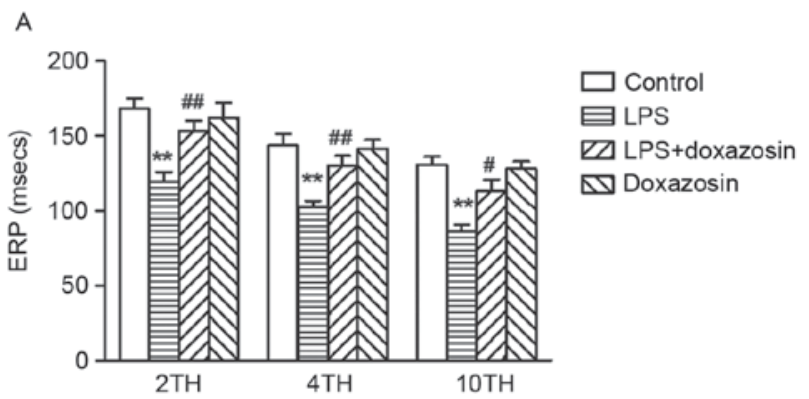

B

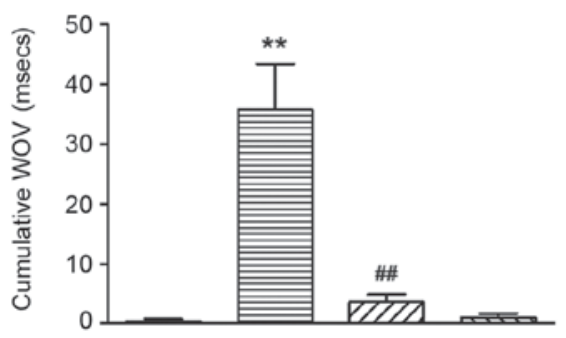

Figure 3.Effect of LPS on atrialERPandWOV incanines.(A)ERPand(B)WOV were measured in canines from the control (vehicle), LPS $(0.1 \mu \mathrm{g} / \mathrm{kg} \mathrm{LPS})$, LPS + doxazosin $(0.1 \mu \mathrm{g} / \mathrm{kg}$ LPS $+0.2 \mathrm{mg} / \mathrm{kg}$ doxazosin $)$ and doxazosin only $(0.2 \mathrm{mg} / \mathrm{kg}$ doxazosin) groups, at the $2 \mathrm{x}, 4 \mathrm{x}$ and $10 \mathrm{x}$ threshold. Data are expressed as the mean \pm standard error ( $\mathrm{n}=5$ /group). ${ }^{* *} \mathrm{P}<0.01 \mathrm{vs}$. control; ${ }^{\#} \mathrm{P}<0.05$ and ${ }^{\# \#} \mathrm{P}<0.01$ vs. LPS. LPS, lipopolysaccharide; ERP, effective refractory periods; 2TH, 2x threshold; 4TH, 4x threshold; 10TH, 10x threshold; WOV, cumulative window of vulnerability.

control; Fig. 3). When compared with the LPS only group, doxazosin prevented the LPS-induced decrease in ERP and increase in WOV $(\mathrm{P}<0.05$; doxazosin + LPS vs. LPS; Fig. 3). In addition, AF was reported in 1/5 dogs in the LPS + doxazosin group ( $\mathrm{P}<0.05$ vs. LPS; data not shown).

Effect of LPS on CX43, TLR4 and NF-kB protein expression. Results from western blot analysis demonstrated that the expression of $\mathrm{Cx} 43$ protein significantly increased in the LPS treated group when compared with the control group $(\mathrm{P}<0.01$; Fig. 4). Immunohistochemistry analysis demonstrated that Cx43 was localized to a large extent in the intercalated disk in the canine atria of the control group. Following treatment with LPS, the amount of Cx43 protein in the area of the intercalated disk increased, and a heterogeneous distribution pattern of Cx43 was identified with a high-density in lateral connection $(\mathrm{P}<0.05$; Fig. 5). Doxazosin only treatment did not influence the expression and distribution of $\mathrm{Cx} 43$ ( $\mathrm{P}>0.05$ vs. control; Figs. 4 and 5). However, in the LPS + doxazosin group, doxazosin inhibited the LPS-induced increase in Cx43 protein and the heterogeneous distribution, when compared with LPS only $(\mathrm{P}<0.01$; Figs. 4 and 5).

TLR4 protein expression in the canine atrium did not increase following 2 weeks of LPS only, LPS + doxazosin or doxazosin only administration. Although LPS treatment did not alter the amount of total $\mathrm{NF}-\kappa \mathrm{B}$ protein expression, it enhanced the nuclear $\mathrm{NF}-\kappa \mathrm{B}$ level in the canine atrial myocardium $(\mathrm{P}<0.01$; Fig. 4), suggesting that LPS may induce the activation of $N F-\kappa B$ and promote the nuclear translocation of $N F-\kappa B$ in the canine atrium. Administration with doxazosin only did not alter the total and nuclear levels of $\mathrm{NF}-\kappa \mathrm{B}$ when compared with 
A

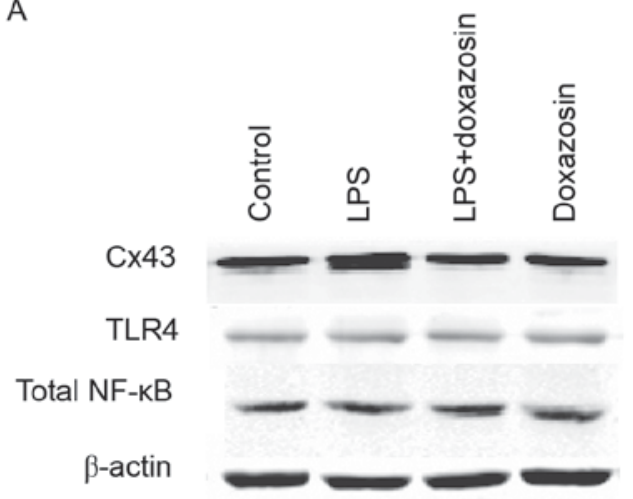

C

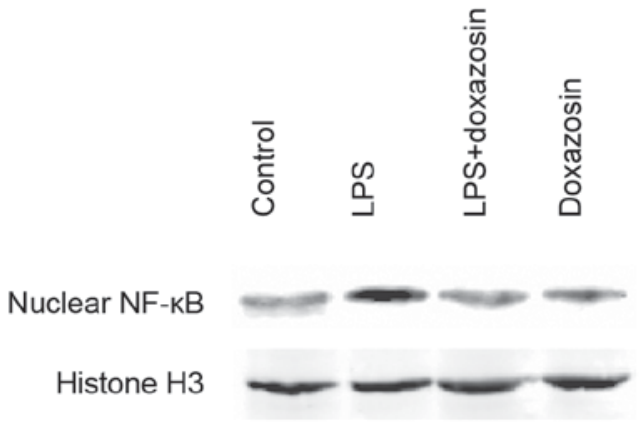

B

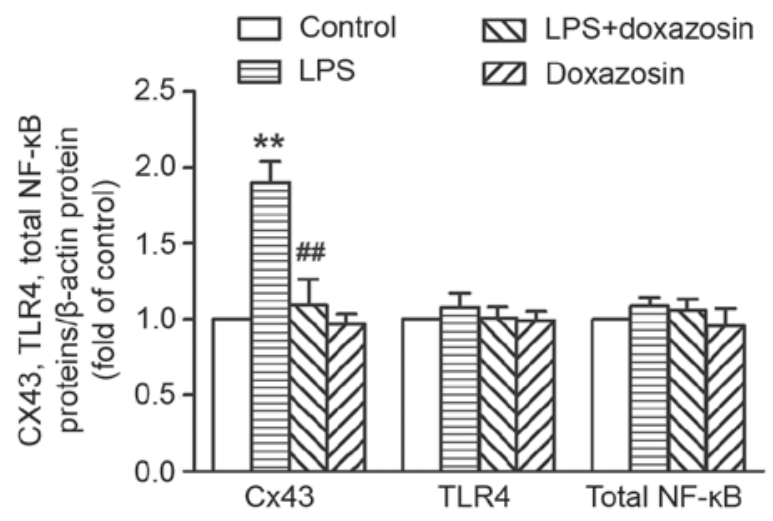

D

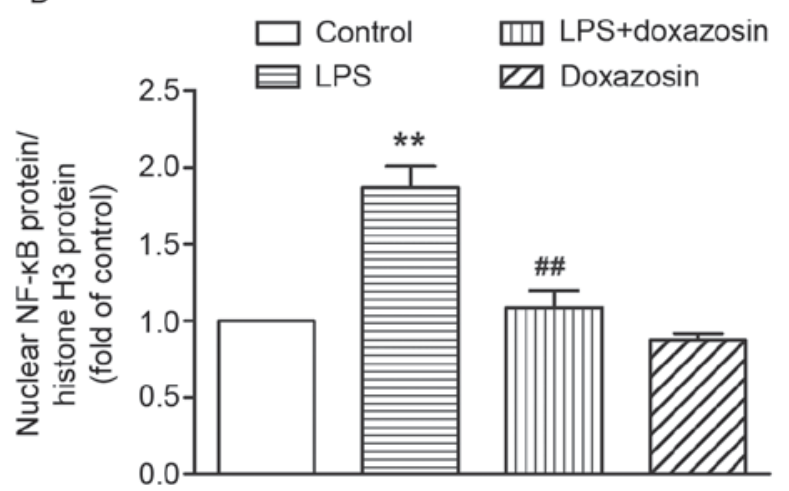

Figure 4. Western blot analysis of Cx43, TLR4 and NF- $\mathrm{KB}$ protein expression in the right atrial tissue. Protein expression was measured in canines from the control (vehicle), LPS $(0.1 \mu \mathrm{g} / \mathrm{kg}$ LPS $)$, LPS + doxazosin $(0.1 \mu \mathrm{g} / \mathrm{kg}$ LPS $+0.2 \mathrm{mg} / \mathrm{kg}$ doxazosin) and doxazosin only $(0.2 \mathrm{mg} / \mathrm{kg}$ doxazosin) groups

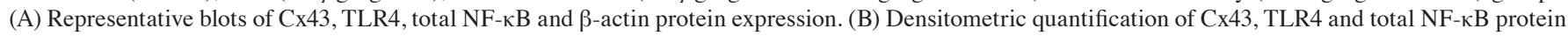
expression normalized to the $\beta$-actin level. Data are expressed as the mean \pm standard error of three experiments and expressed as the fold increase relative to the control $\beta$-actin value. (C) Representative blots of nuclear NF- $\mathrm{KB}$ and histone $\mathrm{H} 3$ protein (nuclear internal protein) expression in nuclear extraction. (D) Densitometric quantification of nuclear NF- $\mathrm{kB}$ protein expression normalized by histone $\mathrm{H} 3$ level. Data are expressed as the mean \pm standard error of three experiments and expressed as the fold increase relative to the control histone $\mathrm{H} 3$ value. ${ }^{* *} \mathrm{P}<0.01$ vs. control group; ${ }^{\# \#} \mathrm{P}<0.01$ vs. LPS. LPS, lipopolysaccharide; Cx43, connexin 43; TLR4, Toll-like receptor 4; TNF- $\alpha$, tumor necrosis factor $\alpha$; NF- $\kappa B$, nuclear factor $\kappa \mathrm{B}$.

control group. However, the level of nuclear NF- $\kappa$ B in the LPS + doxazosin group was significantly lower when compared with the LPS only group ( $\mathrm{P}<0.01$; Figs. 4 and 5).

\section{Discussion}

AF has traditionally been regarded as a sporadic and acquired disease, however, a large population-based cohort study and animal experimental data have suggested that local and systemic inflammation serve an important role in the initiation and perpetuation of AF $(25,26)$. In 2007, Boos et al (27) reported that an LPS challenge as an intravenous bolus of low dose induced a significant increase in acute inflammatory indexes, however, it did not lead to the development of acute new-onset AF in a large cohort of healthy LPS-challenged subjects. However, it has been previously determined that increased risk of AF is mainly associated with low-grade chronic inflammation (28). Low-grade inflammation is induced by a number of systemic diseases including obesity, hypertension and coronary artery disease $(4,26,29)$. Transgenic mice overexpressing TNF- $\alpha$ in the heart have been demonstrated to develop atrial arrhythmias (30). Perfusion with IL-6 >20 min induced an increase in the duration of the action potential in isolated rat atrial tissue and led to the appearance of atrial fibrillation (31). However, whether the subacute treatment of LPS could directly affect cardiac rhythms or induce atrial fibrillation is unclear. In the present study, a chronic low-grade system inflammation model was established by administration of $0.1 \mu \mathrm{g} / \mathrm{kg}$ of LPS once a day for 2 weeks. This dosage of LPS (from Escherichia coli 055:B5) can cause detectable inflammation although no severe clinical symptoms or death $(32,33)$; however, a previous study has demonstrated that using LPS from Escherichia coli 0111:B4 with the same dosage induces severe fever, vomiting, diarrhea and even death in dogs (34). A low-grade subacute or chronic system inflammation model could be established by continuous subcutaneous infusion or repeated daily injection of low dose LPS for $\sim 5$ to 28 days $(35,36)$. Therefore in the present study, LPS from Escherichia coli 055:B5 was used, which was induced only transient fever, vomiting and diarrhea. Although repeated administration of LPS developed an adaptive response in a set of behaviors (such as the febrile response), which was similar to the results of previous studies $(36,37)$, it did induce a system inflammatory response and increase in the inducibility of AF.

In the present study, total $\mathrm{Cx} 43$ protein expression increased in the LPS group dogs, and treatment with LPS increased the expression of the $\mathrm{Cx} 43$ protein in the intercalated disk and also produced a high density distribution of $\mathrm{Cx} 43$ at the lateral 
A

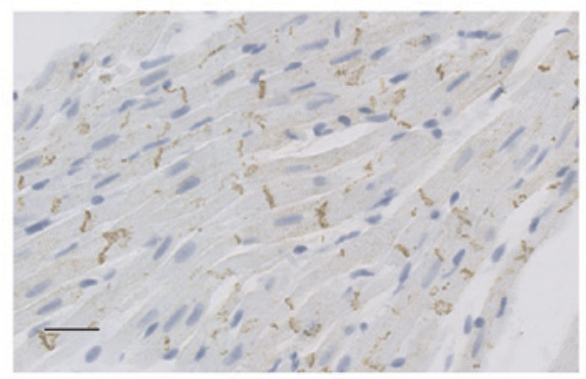

C

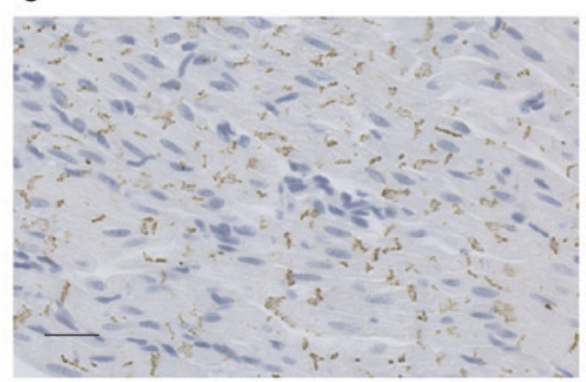

$\mathrm{E}$

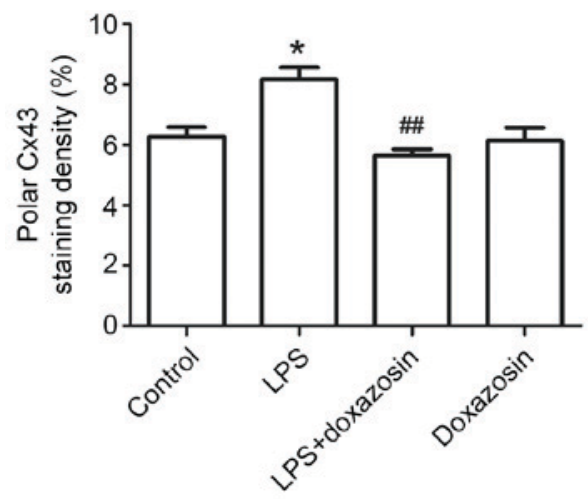

B

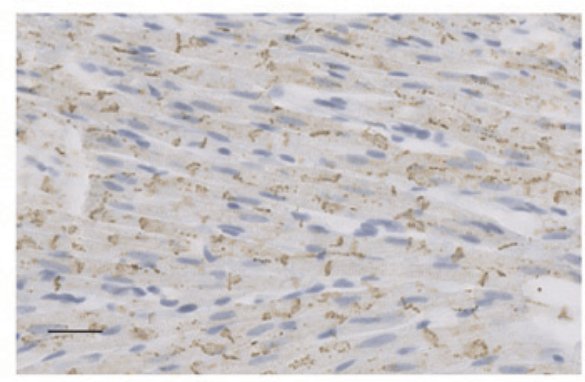

D

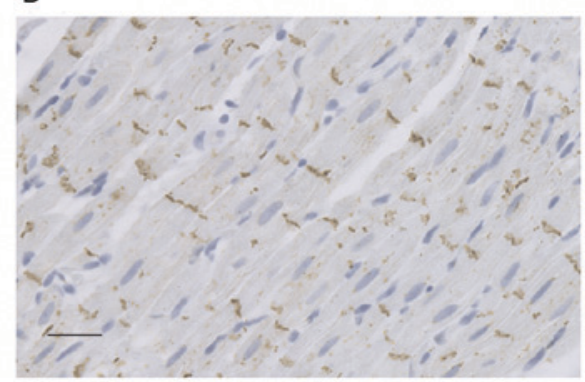

$\mathrm{F}$

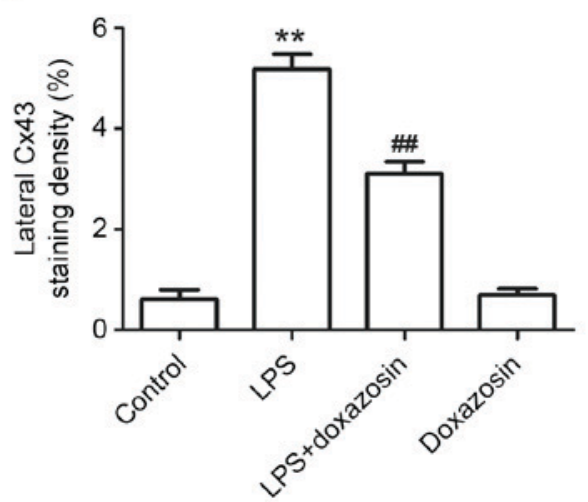

Figure 5. Immunohistostaining of Cx43 in the right atrial tissue. Representative images of the microscopic fields of the atrium immunostained with Cx43 were taken of (A) the control group (vehicle), (B) LPS group (0.1 $\mu \mathrm{g} / \mathrm{kg}$ LPS $),(\mathrm{C}) \mathrm{LPS}+$ doxazosin group $(0.1 \mu \mathrm{g} / \mathrm{kg}$ LPS $+0.2 \mu \mathrm{g} / \mathrm{kg}$ doxazosin) and (D) Doxazosin group $(0.2 \mathrm{mg} / \mathrm{kg}$ doxazosin; magnification, $\mathrm{x} 40$; scale bar=25 $\mu \mathrm{m})$. Quantitative analysis of (E) polar or (F) lateral Cx43 immunolabeled signals in the right atrial tissues was performed. Data are expressed as the mean \pm standard error of three experiments. ${ }^{*} \mathrm{P}<0.05$ and ${ }^{* *} \mathrm{P}<0.01$ vs. control; ${ }^{\# \#} \mathrm{P}<0.01 \mathrm{vs}$. LPS. LPS, lipopolysaccharide; Cx43, connexin 43; TLR4, Toll-like receptor 4; TNF- $\alpha$, tumor necrosis factor $\alpha$.

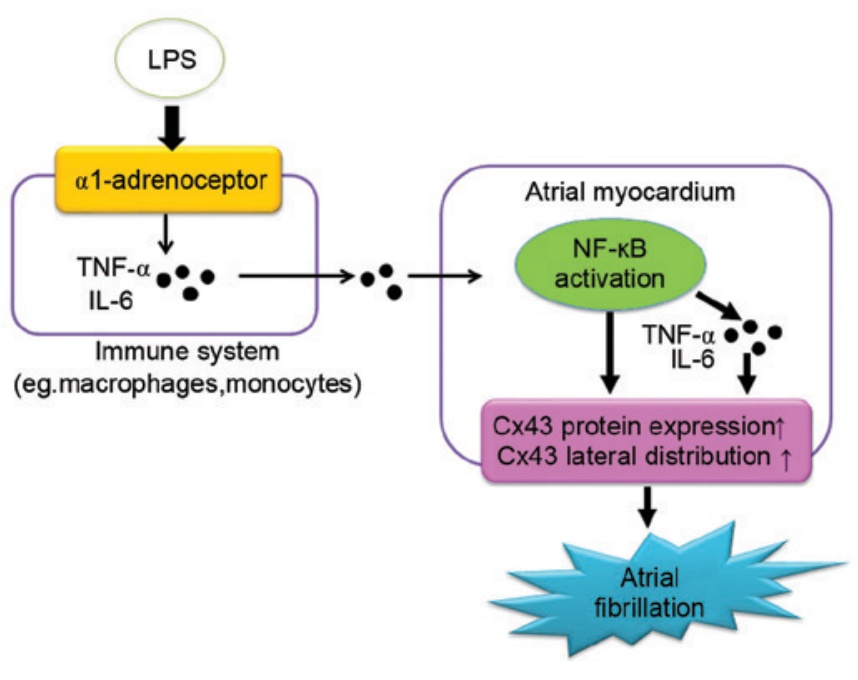

Figure 6. A schematic diagram of chronic low-grade system inflammation and atrial fibrillation. LPS, lipopolysaccharide; TNF- $\alpha$, tumor necrosis factor $\alpha$; IL-6, interleukin 6; NF- $\mathrm{BB}$, nuclear factor $\kappa \mathrm{B}$; $\mathrm{Cx} 43$, connexin 43 . borders of atrial myocytes. Cx43 serves a crucial role in the normal function of the cardiovascular system, and acts as a crucial factor to generate arrhythmias. An increase in Cx43 was identified in patients with lone AF or AF in mitral valve repair when compared with patients in sinus rhythm (38). It has also been reported that atrial $\mathrm{Cx} 43$ expression increased in the canine model of pacing-induced sustained atrial fibrillation $(39,40)$. Somatic genetic defects of Cx43 have been reported as a potential cause of AF in patients with sporadic, nonfamilial lone AF (41). Abnormal distribution of connexins seems to serve a crucial role in the initiation and perpetuation of AF (42). Fastened side-to-side conduction velocity due to an increase in the lateral side of the gap junction may predispose the atrium to reentry (43).

The molecular mechanism of altered Cx43 protein expression and distribution during low-grade systemic inflammation-induced AF is unclear. TNF- $\alpha$ has been suggested as a main mediator of the inflammatory response, contributing to the development of a number of cardiovascular diseases such 
as AF $(30,44)$. TNF- $\alpha$ may change the intracellular distribution of $\mathrm{Cx} 43$ in mouse cardiomyocytes $(45,46)$. The activation of the TLR4 receptor has been known as a classical pathway to increase the production of proinflammatory cytokines (such as TNF- $\alpha$ ) through the phosphorylation of inhibitor of $\kappa \mathrm{B}$ and activation of $N F-\kappa B$ (47). TLR4 expression has been detected in the atrium (48). In the present study, administration of low-dose LPS for 2 weeks led to the activation of NF- $\kappa \mathrm{B}$ and significantly increased the levels of TNF- $\alpha$ and IL- 6 in the atria, however, it did not alter TLR4 expression.

An increasing body of evidence has demonstrated that there is a cross-talk between $\alpha 1-\mathrm{AR}$ signaling and cytokine production. Catecholamines have been reported to be produced by phagocytes and enhance acute inflammatory injuries (18). In human monocytes and macrophages, $\alpha 1-\mathrm{AR}$ positively regulates the LPS-induced cytokine production (IL-1 $\beta$ ) production (49). Stimulation of $\alpha 2$-AR augments the production of TNF- $\alpha$ in vitro from alveolar macrophage (50). Panama et al (51) identified that activation of $\alpha 1-\mathrm{AR}$ regulates the fast transient outward $\mathrm{K}^{+}$current in rat ventricular myocytes via the $\mathrm{NF}-\kappa \mathrm{B}$-dependent signaling pathway. Neuronally induced atrial arrhythmias can be modified if a $\alpha$-AR blockade targets the intrinsic cardiac local circuit of neurons (52). In the present study, blockage of $\alpha 1-A R$ inhibited NF- $\kappa \mathrm{B}$ activation, and the production of TNF- $\alpha$ and IL- 6 , suggesting that $\alpha 1$-AR may participate in the LPS-induced NF- $\mathrm{B}$ activation in canine hearts. The LPS-induced decrease in $\mathrm{Cx} 43$ and increase in inducibility of AF was also inhibited by an $\alpha 1-A R$ antagonist, indicating that $\alpha 1$-adrenergic activation may be involved in the low-grade system of inflammation-induced AF (Fig. 6).

One of the limitations of the present study was that the effect of infiltrated monocytes and activated endothelium, which may also contribute to the mechanism of the low-grade system of inflammation-induced AF, cannot be excluded. Recruitment of immune cells across the atrial endocardium has been observed in human AF (53), and immune cells (such as monocytes and macrophages) are the stronger regulator in the production of LPS-induced inflammatory cytokines (49). It is possible that infiltrated monocytes and activated endothelium are also involved in LPS-induced cytokine generation in the heart. Besides Cx43, Cx40 is another major composition of gap junctions expressed in the atrium (54). It will be of interest to examine whether the changes in Cx40 expression or distribution are also involved in this canine model of inflammation-induced AF.

In conclusion, administration of a low-dose of LPS for 2 weeks generated a system inflammatory response and increased the inducibility of AF in the canine model. The mechanism may be involved in the LPS-induced activation of $\mathrm{NF}-\kappa \mathrm{B}$, and the increase in $\mathrm{Cx} 43$ expression and lateral distri-

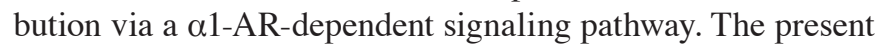
study will help to further elucidate the pathogenesis of the system inflammation-induced atrial fibrillation, and provide novel ideas for the occurrence of atrial fibrillation.

\section{Acknowledgements}

The present study was supported by the National Natural Science Foundation of China (grant nos. 81170167, 81,270,002 and 81471837) and the Science and Technology Department of Zhejiang Province (grant no. 2015C37129).

\section{References}

1. Desai NR and Giugliano RP. Can we predict outcomes in atrial fibrillation? Clin Cardiol 35 (Suppl 1): S10-S14, 2012.

2. Zoni-Berisso M, Lercari F, Carazza T and Domenicucci S. Epidemiology of atrial fibrillation: European perspective. Clin Epidemiol 6: 213-220, 2014

3. Leonardi M and Bissett J: Prevention of atrial fibrillation. Curr Opin Cardiol 20: 417-423, 2005.

4. Harada M, Van Wagoner DR and Nattel S: Role of inflammation in atrial fibrillation pathophysiology and management. Circ J 79: 495-502, 2015.

5. Pellegrino PL, Brunetti ND, De Gennaro L, Ziccardi L, Grimaldi $M$ and Biase MD: Inflammatory activation in an unselected population of subjects with atrial fibrillation: Links with structural heart disease, atrial remodeling and recent onset. Intern Emerg Med 8: 123-128, 2013.

6. Chen MC, Chang JP, Liu WH, Yang CH, Chen YL, Tsai TH, Wang YH and Pan KL: Increased inflammatory cell infiltration in the atrial myocardium of patients with atrial fibrillation. Am J Cardiol 102: 861-865, 2008.

7. Marcus GM, Smith LM, Ordovas K, Scheinman MM, Kim AM, Badhwar N, Lee RJ, Tseng ZH, Lee BK and Olgin JE: Intracardiac and extracardiac markers of inflammation during atrial fibrillation. Heart Rhythm 7: 149-154, 2010.

8. Li J, Solus J, Chen Q, Rho YH, Milne G, Stein CM and Darbar D: Role of inflammation and oxidative stress in atrial fibrillation. Heart Rhythm 7: 438-444, 2010.

9. Friedrichs K, Adam M, Remane L, Mollenhauer M, Rudolph V, Rudolph TK, Andrié RP, Stöckigt F, Schrickel JW, Ravekes $\mathrm{T}$, et al: Induction of atrial fibrillation by neutrophils critically depends on CD11b/CD18 integrins. PLoS One 9: e89307, 2014.

10. Pinho-Gomes AC, Reilly S, Brandes RP and Casadei B: Targeting inflammation and oxidative stress in atrial fibrillation: Role of 3-hydroxy-3-methylglutaryl-coenzyme a reductase inhibition with statins. Antioxid Redox Signal 20: 1268-1285, 2014.

11. Ozaydin M, Icli A, Yucel H, Akcay S, Peker O, Erdogan D, Varol E, Dogan A and Okutan H: Metoprolol vs. carvedilol or carvedilol plus N-acetyl cysteine on post-operative atrial fibrillation: A randomized, double-blind, placebo-controlled study. Eur Heart J 34: 597-604, 2013.

12. Thomsen MB: Strengthening intercellular communication to prevent atrial fibrillation. Cardiovasc Res 92: 187-188, 2011

13. Gros DB and Jongsma HJ: Connexins in mammalian heart function. Bioessays 18: 719-730, 1996.

14. Rothe S, Busch A, Bittner H, Kostelka M, Dohmen PM, Mohr FW and Dhein S: Body mass index affects connexin43 remodeling in patients with atrial fibrillation. Thorac Cardiovasc Surg 62: 547-553, 2014.

15. Bikou O, Thomas D, Trappe K, Lugenbiel P, Kelemen K, Koch M, Soucek R, Voss F, Becker R, Katus HA and Bauer A: Connexin 43 gene therapy prevents persistent atrial fibrillation in a porcine model. Cardiovasc Res 92: 218-225, 2011.

16. Yan J, Kong W, Zhang Q, Beyer EC, Walcott G, Fast VG and Ai X: c-Jun N-terminal kinase activation contributes to reduced connexin43 and development of atrial arrhythmias. Cardiovasc Res 97: 589-597, 2013.

17. Shin SY, Jo WM, Min TJ, Kim BK, Song DH, Hyeon SH, Kwon JE, Lee WS, Lee KJ, Kim SW, et al: Gap junction remodelling by chronic pressure overload is related to the increased susceptibility to atrial fibrillation in rat heart. Europace 17: 655-663, 2015.

18. Flierl MA, Rittirsch D, Nadeau BA, Chen AJ, Sarma JV, Zetoune FS, McGuire SR, List RP, Day DE, Hoesel LM, et al: Phagocyte-derived catecholamines enhance acute inflammatory injury. Nature 449: 721-725, 2007.

19. Lu H, Xu M, Wang F, Liu S, Gu J and Lin S: Chronic stress enhances progression of periodontitis via $\alpha 1$-adrenergic signaling: A potential target for periodontal disease therapy. Exp Mol Med 46: e118, 2014.

20. Al-Hashem FH, Assiri AS, Shatoor AS, Elrefaey HM, Alessa RM and Alkhateeb MA: Increased systemic low-grade inflammation in high altitude native rats mediated by adrenergic receptors. Saudi Med J 35: 538-546, 2014. 
21. The National Academies Collection: Reports funded by National Institutes of Health: National Research Council (US) Committee for the Update of the Guide for the Care and Use of Laboratory Animals. Guide for the Care and Use of Laboratory Animals 8th edition. National Academies Press (US), Washington (DC), pp1-197, 2011.

22. Lu Z, Scherlag BJ, Lin J, Niu G, Fung KM, Zhao L, Ghias M, Jackman WM, Lazzara R, Jiang H and Po SS: Atrial fibrillation begets atrial fibrillation: Autonomic mechanism for atrial electrical remodeling induced by short-term rapid atrial pacing. Circ Arrhythm Electrophysiol 1: 184-192, 2008.

23. Rashid A, Hines M, Scherlag BJ, Yamanashi WS and Lovallo W: The effects of caffeine on the inducibility of atrial fibrillation. J Electrocardiol 39: 421-425, 2006.

24. Bode F, Katchman A, Woosley RL and Franz MR: Gadolinium decreases stretch-induced vulnerability to atrial fibrillation. Circulation 101: 2200-2205, 2000.

25. Aviles RJ, Martin DO, Apperson-Hansen C, Houghtaling PL, Rautaharju P, Kronmal RA, Tracy RP, Van Wagoner DR, Psaty BM, Lauer MS and Chung MK: Inflammation as a risk factor for atrial fibrillation. Circulation 108: 3006-3010, 2003.

26. Hu YF, Chen YJ, Lin YJ and Chen SA: Inflammation and the pathogenesis of atrial fibrillation. Nat Rev Cardiol 12: 230-243, 2015.

27. Boos CJ, Lip GY and Jilma B: Endotoxemia, inflammation, and atrial fibrillation. Am J Cardiol 100: 986-988, 2007.

28. Liuba I, Ahlmroth H, Jonasson L, Englund A, Jönsson A, Säfström K and Walfridsson H: Source of inflammatory markers in patients with atrial fibrillation. Europace 10: 848-853, 2008.

29. Goudis CA, Ntalas IV and Ketikoglou DG: Atrial fibrillation in athletes. Cardiol Rev 23: 247-251, 2015.

30. Saba S, Janczewski AM, Baker LC, Shusterman V, Gursoy EC, Feldman AM, Salama G, McTiernan CF and London B: Atrial contractile dysfunction, fibrosis, and arrhythmias in a mouse model of cardiomyopathy secondary to cardiac-specific overexpression of tumor necrosis factor-\{alpha\}. Am J Physiol Heart Circ Physiol 289: H1456-H1467, 2005.

31. Mitrokhin VM, Mladenov MI and Kamkin AG: Effects of interleukin- 6 on the bio-electric activity of rat atrial tissue under normal conditions and during gradual stretching. Immunobiology 220: 1107-1112, 2015.

32. Flatland B, Fry MM, LeBlanc CJ and Rohrbach BW: Leukocyte and platelet changes following low-dose lipopolysaccharide administration in five dogs. Res Vet Sci 90: 89-94, 2011.

33. LeBlanc CJ, Horohov DW, Bauer JE, Hosgood G and Mauldin GE: Effects of dietary supplementation with fish oil on in vivo production of inflammatory mediators in clinically normal dogs. Am J Vet Res 69: 486-493, 2008.

34. LeMay DR, LeMay LG, Kluger MJ and D'Alecy LG: Plasma profiles of IL-6 and TNF with fever-inducing doses of lipopolysaccharide in dogs. Am J Physiol 259: R126-R132, 1990.

35. Cani PD, Amar J, Iglesias MA, Poggi M, Knauf C, Bastelica D, Neyrinck AM, Fava F, Tuohy KM, Chabo C, et al: Metabolic endotoxemia initiates obesity and insulin resistance. Diabetes 56: 1761-1772, 2007

36. Sparkman NL, Martin LA, Calvert WS and Boehm GW: Effects of intraperitoneal lipopolysaccharide on Morris maze performance in year-old and 2-month-old female C57BL/6J mice. Behav Brain Res 159: 145-151, 2005.

37. Marais M, Maloney SK and Gray DA: The development of endotoxin tolerance, and the role of hypothalamo-pituitary-adrenal function and glucocorticoids in Pekin ducks. J Exp Biol 214: 3378-3385, 2011.

38. Wetzel U, Boldt A, Lauschke J, Weigl J, Schirdewahn P, Dorszewski A, Doll N, Hindricks G, Dhein S and Kottkamp H: Expression of connexins 40 and 43 in human left atrium in atrial fibrillation of different aetiologies. Heart 91: 166-170, 2005.
39. Sakabe M, Fujiki A, Nishida K, Sugao M, Nagasawa $H$, Tsuneda T, Mizumaki K and Inoue H: Enalapril prevents perpetuation of atrial fibrillation by suppressing atrial fibrosis and over-expression of connexin43 in a canine model of atrial pacing-induced left ventricular dysfunction. J Cardiovasc Pharmacol 43: 851-859, 2004.

40. Elvan A, Huang XD, Pressler ML and Zipes DP: Radiofrequency catheter ablation of the atria eliminates pacing-induced sustained atrial fibrillation and reduces connexin 43 in dogs. Circulation 96: 1675-1685, 1997.

41. Thibodeau IL, Xu J, Li Q, Liu G, Lam K, Veinot JP, Birnie DH, Jones DL, Krahn AD, Lemery R, et al: Paradigm of genetic mosaicism and lone atrial fibrillation: Physiological characterization of a connexin 43-deletion mutant identified from atrial tissue. Circulation 122: 236-244, 2010.

42. Duffy HS and Wit AL: Is there a role for remodeled connexins in AF? No simple answers. J Mol Cell Cardiol 44: 4-13, 2008.

43. Verheule S, Wilson EE, Arora R, Engle SK, Scott LR and Olgin JE: Tissue structure and connexin expression of canine pulmonary veins. Cardiovasc Res 55: 727-738, 2002.

44. Ren M, Li X, Hao L and Zhong J: Role of tumor necrosis factor alpha in the pathogenesis of atrial fibrillation: A novel potential therapeutic target? Ann Med 47: 316-324, 2015.

45. Liew R, Khairunnisa K, Gu Y, Tee N, Yin NO, Naylynn TM and Moe KT: Role of tumor necrosis factor- $\alpha$ in the pathogenesis of atrial fibrosis and development of an arrhythmogenic substrate. Circ J 77: 1171-1179, 2013.

46. Sawaya SE, Rajawat YS, Rami TG, Szalai G, Price RL, Sivasubramanian N, Mann DL and Khoury DS: Downregulation of connexin40 and increased prevalence of atrial arrhythmias in transgenic mice with cardiac-restricted overexpression of tumor necrosis factor. Am J Physiol Heart Circ Physiol 292: H1561-H1567, 2007.

47. Baumgarten G, Knuefermann P, Nozaki N, Sivasubramanian N, Mann DL and Vallejo JG: In vivo expression of proinflammatory mediators in the adult heart after endotoxin administration: The role of toll-like receptor-4. J Infect Dis 183: 1617-1624, 2001.

48. Katoh S, Honda S, Watanabe T, Suzuki S, Ishino M, Kitahara T, Funayama A, Netsu S, Sasaki T, Shishido T, et al: Atrial endothelial impairment through Toll-like receptor 4 signaling causes atrial thrombogenesis. Heart Vessels 29: 263-272, 2014.

49. Grisanti LA, Woster AP, Dahlman J, Sauter ER, Combs CK and Porter JE: $\alpha 1$-adrenergic receptors positively regulate Toll-like receptor cytokine production from human monocytes and macrophages. J Pharmacol Exp Ther 338: 648-657, 2011.

50. Spengler RN, Allen RM, Remick DG, Strieter RM and Kunkel SL. Stimulation of alpha-adrenergic receptor augments the production of macrophage-derived tumor necrosis factor. J Immunol 145: 1430-1434, 1990.

51. Panama BK, Latour-Villamil D, Farman GP, Zhao D, Bolz SS, Kirshenbaum LA and Backx PH: Nuclear factor kappaB downregulates the transient outward potassium current I(to,f) through control of KChIP2 expression. Circ Res 108: 537-543, 2011.

52. Richer LP, Vinet A, Kus T, Cardinal R, Ardell JL and Armour JA: Alpha-adrenoceptor blockade modifies neurally induced atrial arrhythmias. Am J Physiol Regul Integr Comp Physiol 295: R1175-R1180, 2008.

53. Yamashita T, Sekiguchi A, Iwasaki YK, Date T, Sagara K, Tanabe H, Suma H, Sawada H and Aizawa T: Recruitment of immune cells across atrial endocardium in human atrial fibrillation. Circ J 74: 262-270, 2010.

54. Verheule S, van Kempen MJ, te Welscher PH, Kwak BR and Jongsma HJ: Characterization of gap junction channels in adult rabbit atrial and ventricular myocardium. Circ Res 80: 673-681, 1997. 